\title{
The Latin American and Nigerian Conditional Cash Transfer Experience: A Comparative Analysis
}

\author{
Ikenna Samuel Umezurike (Corresponding Author) \\ Department of Public Administration \\ University of Calabar, Nigeria \\ Ibraheem Salisu Adam, Ph.D. \\ National Cash Transfer Office, Abuja, Nigeria
}

Received: Dec. 26, 2019 Accepted: Jul. 6, 2020 Online published: Jul. 15, 2020

doi:10.5296/jpag.v10i3.16142ＵRL: https://doi.org/10.5296/jpag.v10i3.16142

\begin{abstract}
Despite the recent economic growth in Nigeria, poverty remains a social problem. One of the strategies employed by the Nigerian government and some development partners towards solving this problem is the deployment of social protection instruments, such as Conditional Cash Transfers (CCTs), which aim at stemming the tide of poverty and vulnerability. This study uses the secondary research method to examine the extent to which the Latin American CCT model influenced the design and operation of the Nigerian CCT programme. The policy diffusion model adopted for the study posits that the success of CCT programmes in Latin America has stimulated its extension to many developing countries outside the region. The findings from the review of selected literature explain the rationale for CCTs as short-term poverty reduction and long-term human capital development. Admittedly, a nexus exists between the Latin American and Nigerian strategies. Yet the study concludes that the Latin American model cannot adequately serve as a blueprint for the Nigeria strategy, given that underlying conditions in upper middle-income Latin American countries are clearly different from those present in low income or lower middle-income African countries like Nigeria. The study recommends urgent implementation of the National Social Protection Policy; a review of the current CCT programme in Nigeria every two years and extensive research into social protection strategies.
\end{abstract}

Keywords: conditional cash transfers, social protection, poverty, policy diffusion, oportunudades (opportunities), Bolsa familia (family allowance), household uplifting programme 


\section{Introduction}

In recent decades, poverty alleviation and eradication have received much attention in international development and poverty research. Consequently, a steady decline in the global population of people living below USD $\$ 1.25$ per day has been experienced, from 37.1 per cent in 1990 to 12.8 per cent by 2012 (World Bank, 2017). This success arguably influenced world leaders to adopt the ambitious Sustainable Development Goal in 2015, "to eradicate extreme poverty for all people everywhere by 2030" (Saunders, 2018). Globally, Conditional Cash Transfer (CCT) programmes are becoming increasingly popular among developing countries as tools for poverty alleviation and advancing child health and education outcomes. Development partners such as the World Bank and other international financial institutions support these initiatives. The evolution of CCT programmes began in Latin America in the mid-1990s. Back then, the CCT programme aimed at cushioning the socio-economic effects of the debt crisis of the 1980s, as well as the financial crises that affected Mexico and several countries in Asia (Legarde, Haines and Palmer, 2009). The success of these programmes has served as a stimulus to the extension of similar programmes in many other developing countries outside Latin America. Some countries with CCT programme experience include Mexico, Honduras, Nicaragua, Brazil, Turkey, Mozambique (Attanasio, Battistin, Fitzsimons, Mesnard and Vera-Hernandez, 2005), India, Nepal, Ecuador, Jamaica and Kenya (Legarde et al, 2009).

Dauda (2017) has opined that in recent years the poverty trend in Nigeria differs from other countries, despite economic growth poverty remains a recurring social problem in the country. Between 1980 and 2004, rural poverty increased in Nigeria from 28.3 per cent to 63.3 per cent, and urban poverty from 17.2 per cent to 43.2 per cent (UNDP, 2009). As at 2005, approximately 75 million of the 140 million population were poor (Holmes, Samson, Magoronga, and Akinrimisi, 2011), and according to the National Bureau of Statistics the number of persons in absolute poverty increased to 102.2 million in 2010 (NBS, 2010). In addition, high rates of unemployment and limited business opportunities in the rural and urban areas continue to restrict the economic opportunities available to men, women, and youths, thereby increasing poverty rates (Holmes et al, 2011).

In the past, Nigeria has implemented several poverty reduction strategies that include Operation Feed Nigeria (1976); Better Life for Rural Women (1987); Family Support Programme (1994); Family Economic Advancement Programme (1997); Poverty Alleviation Programme (2000); National Poverty Eradication Programme (2001); and the National Economic Empowerment and Development Strategy (2003). Notwithstanding all these, poverty eradication has remained a mirage in Nigeria (Danaan, 2018). It is in this vein that Federal Government of Nigeria developed a social reform programme - National Social Safety Nets Project (NASSP) as a sustainable tool in addressing the increasing rate of poverty and vulnerability. The Household Uplifting Programme (HUP), which is one of the components of the NASSP, is concerned with cash transfers to the poor and vulnerable groups in Nigeria. Some of the main objectives of this component are to enhance the consumption levels of the poorest and most vulnerable households, establish sustainable livelihood for the beneficiaries, and ensure social and financial inclusion (FGN, 2016). 
Hence, to what extent is the Nigerian conditional cash transfer programme influenced by the Latin American experience? What are the possible challenges of the adoption of the Latin American model to the conditional cash transfer strategy in Nigeria? Accordingly, the primary objective of this paper is to determine whether a nexus exists between the Nigerian CCT programme and the Latin American CCT model.

\section{Literature Review}

Africa has recorded increased economic growth rates in recent years. According to the African Development Bank (2018), real output growth of African countries increased from 2.2 per cent in 2016 to 3.6 per cent in 2017; and up again to an estimated 4.1 per cent in 2018 and 2019. It is also reported that 39 out of 43 countries in sub-Saharan Africa have achieved higher per capita GDP levels in 2013 compared to year 2000 (Arndt, McKay and Tarp, 2016); and an estimated GDP growth from 5.3 per cent in 2014, to 5.5 per cent in 2015. At the same time, sub-Saharan Africa has experienced a marked decline in the poverty rate, from 58 per cent in 1999 to 48 per cent in 2010 (Oluwatayo and Ojo, 2018). Arguably, the proliferation of several social protection strategies in the continent that enhanced human capital development, have been responsible for this progress in poverty reduction. Akinola (2017) mentioned two models of social protection that are predominant in sub-Saharan Africa, namely: The Aged-Based Model (common to Southern Africa) and the Poverty-Based Model (common in East, Central, and West Africa). Programmes under the Age-Based Model are usually long-term and include child benefits and social pensions for the elderly. Poverty-based programmes on the other hand, are relatively short-term and include cash transfers aimed at cushioning the effects of poverty in poor households and to vulnerable groups such as women, children, and unemployed youths. The latter model forms the basis for the recently adopted Cash Transfer strategies that include Conditional Cash Transfers, Cash for Work Initiatives, Unconditional Cash Transfers, Social Pensions, Child Grants, and Disability Grants.

However, what are Cash Transfers? Cash Transfers refer to the provision of aid in the form of cash, with the goal of increasing the real income of the poor or those who face a probable risk of falling into poverty (Legarde, et al, 2009). Lund, Noble, Barnes and Wright (2008) have further described cash transfers as a regular amount of money distributed directly to groups such as the elderly, the unemployed, or children. Cash Transfers are mostly conditional; meaning that stipends are paid to eligible households on the condition of certain behavioural change. In other words, CCTs can be used to pay recipients in exchange for an action that brings private behaviour closer to the social optimum (De Janvry and Sadoulet 2005), and help beneficiaries to avoid inappropriate actions such as undesirable spending (Schubert and Slater, 2006). Essentially, CCTs not only ensure more consumption, but also consumption of items preferred by the funder. These monetary transfers are made to households, on the condition that they make pre-specified human capital investments in their children, such as sending school-age children to school and taking younger children for regular visits to health care facilities (Fiszbien and Schady, 2009; Schady and Araujo, 2008; Attanasio et al, 2005).

Besides their short-term benefits, CCTs also function as social assistance instruments designed to achieve not only short-term poverty reduction, but also long-term human capital 
investment (Chapman, 2006; Sandberg, 2015). The latter factor is a primary difference between CCT and in-kind Transfers. In-kind transfers (such as the provision of food or food stamps) supply short-term benefit, but present logistic challenges that make it more expensive to execute. The long-term human capital development factor is the reason many CCT programmes target the health and education of school-age children (National Cash Transfer Office, 2017).

There are varying arguments in scholarly literature on the benefits of CCTs and the consequences of conditionality; the appropriateness of conditional transfers as against unconditional transfers; and targeting and universal coverage. Advocates of rights-based approaches to social protection argue that the use of conditionality in CCTs is antithetical to the idea of social protection as a human right (Standing 2014; Freeland 2007). Freeland (2007) specifically described CCTs as physically pernicious, politically abominable, economically superfluous, and morally atrocious. He further argues that if improved school and clinic attendance by the poor were the objective, the best way would be to improve primary education and health services close to where poor people live, not by imposing conditionality. Again, Hanlon, Barrientos and Hulme (2010) argue that simply giving money to the poor without any strings attached may be the most promising approach not just for avoiding hardship and reducing poverty, but also for long-term development. Freeland (2007) also itemises overstretched health and education services, weak government administrative capacity, already high school enrolment rate (especially in countries where primary education is free), and complexity of monitoring CCTs, as further reasons why cash transfers should be unconditional in Africa.

On the other hand, Schubert and Slater (2006) being proponents of conditionality, identified some rationale behind the linking of conditionality to social cash transfers. First, funding agencies believe that poverty relates to inadequate access to nutrition, health, education, or housing. Second, programme designers try to influence the behaviour and attitudes of target households. Finally, programme designers are convinced that conditional cash transfer schemes are more acceptable to policy makers and taxpayers than unconditional cash transfer schemes. Other proponents of conditionality argue based on increased school enrolments (Whetten, Fontenla and Villa, 2019; Garcia, Harker and Ricaurte, 2016; Schady and Araujo, 2008), and improved access to health services and nutrition for poor households and communities (Owusu-Addo, Ranzaho and Smith, 2019; Lagarde et al, 2009; Attanasio et al, 2005). Further, some argue that conditionality in CCTs can be helpful, as long as countries move towards the progressive realisation of universal rights, and also provide access without excluding anyone in need (Orton 2014; Sepulveda 2011).

\section{Research Method}

The qualitative research method with an underlying exploratory approach was adopted for this research. Several secondary data sources, such as books, journals, theses, official Government publications and public documents such as World Bank reports, were explored and analysed using critical reading and content analysis. This approach was necessary to identify patterns in the programmes under study. In order to consolidate on the Latin 
American experience, scholarly literature about the conditional cash transfer programmes of Mexico and Brazil were sourced through the internet using several scholarly databases, including the British Ethos Library. Keywords such as "conditional cash transfer Latin America", "Bolsa Familia Brazil" "Oportunudades Mexico" were used to find related studies and articles. The search results were limited to full text English language sources. The National Cash Transfer Office website and other operational documents supplied data on the Household Uplifting Programme.

\section{Policy Diffusion and Conditional Cash Transfers}

Noteworthily, the early approaches to the concept of diffusion (first studied by Gabriel Tarde, a French sociologist in the late nineteenth century) influenced studies on policy diffusion (Kinnunen, 1996). Everett Rogers, a Professor of Rural Sociology further developed this concept in his 1962 book, entitled Diffusion of Innovations. The book compiled about 600 studies on diffusion across several fields such as industrial sociology, medical sociology, rural sociology, education, and anthropology; where the concept of diffusion was defined as the process in which an innovation (an idea) is communicated through certain channels over time among the members of a social system. Four key elements or components are derived from these, namely: innovation, communication channels, time, and social system. Rogers described Innovation as an idea, practice, or project that is perceived as new by an individual or other unit of adoption (Rogers, 2003), and Communication as a process in which participants create and share information with one another in order to reach a mutual understanding. Further, he defined the Social System as a set of interrelated units engaged in joint problem solving to accomplish a common goal. In Rogers', view the five attributes of an innovation, which include relative advantage, compatibility, complexity, observability, and trialability, determine the rate of diffusion.

While giving reasons for policy diffusion, Berry and Berry (2007) identified three causal mechanisms for diffusion of polices: Learning, Competition, and Coercion. Learning occurs when policy makers look for faster means of solving complex societal problems, in which they borrow promising innovations or draw lessons from successful experiences of other countries or institutions. In this respect, the policymakers evaluate the consequences of policies formulated elsewhere before planning (Gilardi and Wasserfallen, 2018). Another mechanism is Competition, which results from the race for scarce resources. This connotes that countries imitate policies of other countries to achieve economic advantage over others. Coercion on the other hand explains that countries can be pressured to adopt policies that have been widely adopted by other countries or can be forced to adopt a policy. To illustrate, a powerful international organisation or country may pressure another country to make certain policy changes in exchange for economic incentives. Nevertheless, other studies added Emulation as the fourth mechanism for diffusion of policies (Graham, Shipan and Volden, 2013; Obinger, Schmitt and Starke, 2013; Gilardi and Wasserfallen, 2018); and relate Emulation to the processes of socialisation, where actors copy from others. Although Emulation is noted to focus on the political dimension of diffusion, it is often regarded as a residual category (Gilardi and Wasserfallen, 2018). 
It is clear in the extant literature that the occurrence of policy diffusion focuses on two aspects - horizontal diffusion and vertical diffusion. Obinger et al (2013) posit that horizontal diffusion takes place when policies and programmes diffuse from one country to another. Vertical diffusion on the other hand, takes place when policies and programmes developed or advanced by international organisations diffuse into a polity or country. Motta (2018) noted that there are more studies on horizontal diffusion than vertical diffusion. Kuhlmann, De Refuels, Schlichte and Nullmeier (2019) expanded this classification by deriving four constellations of diffusion, namely: Country-to-Country Diffusion, International Organisation-to-Country Diffusion, Country-to-International Organisation Diffusion and Imperial Diffusion (from a dominant government to a legally dependent government or unit).

In relation to the above, vertical diffusion can be regarded as a feature of policy diffusion in Latin America. Geographical proximity is a factor, as Oliveira and De Faria (2017) have noted, a cluster of countries or governments who find themselves in a given geographical space has adopted most policies. The role of international organisations in the diffusion of social protection policies throughout Latin America further emphasizes the coercion mechanism. The spread of CCTs throughout Latin America is due to pressure on states by international organisations, using a platform known as "learning from your neighbours", and financial incentives to encourage adoption (Sugiyama, 2011). For instance, the United Kingdom's Department for International Development (DFID) and the World Bank provided financial and technical support to Bolsa Familia (Howlett, Ramesh and Saguin, 2018). While working with Mexico and Brazil, these organisations (and the many consultants who work with them) have played a central role as agents of diffusion, and have assisted in generating and packaging information on the effectiveness of CCT programmes to many countries seeking to strengthen their social protection strategies at low cost (Howlett et al, 2018).

On the other hand, the diffusion of CCT programmes to the rest of the developing world, especially sub-Saharan Africa, has not followed a similar pattern. The adoption of CCT programmes in Nigeria follows the learning mechanism of policy diffusion. Nigeria's CCT experience did not start with the HUP, which succeeds several types of Federal and State Government CCT programmes. As such, the articulation of the HUP has factored in the consequences of earlier and existing local and transnational cash transfer programmes. For instance, COPE (In Care of the Poor) is a CCT programme launched in 2007 that has remained in existence up until the time the HUP began in 2016. The primary aim of COPE was to reduce intergenerational poverty and build human capital of poor and vulnerable households, like the goals of the Latin American CCT programmes (Akinola, 2014). Invariably, the Nigerian CCT experience can aid the understanding of horizontal or country-to-country policy diffusion.

\section{Overview of the Latin American and Nigerian Strategies}

\subsection{Mexico: Oportunidades}

Mexico is known globally for the implementation of the first successful CCT programme, Progresa (later known as Oportunidades). The programme began in 1997 as a response to severe financial and economic crisis that emerged in 1994. It was a large-scale poverty 
alleviation programme that aimed at supplying short-term relief from poverty and long-term poverty eradication through investment in human capital (Parker, 2003). In line with this objective, small amounts of money were disbursed to poor families based on strict conditions that children regularly attend school and family members that obtain preventive medical care through regular medical check-ups. Oportunidades provides these families with the equivalent of the income they could have gotten from child labour if they send their children to school. Overall, as long as families adhere to the prescribed conditions, they are free to spend the cash transfers as they wish. Oportunidades gradually became the largest single poverty alleviation programme in Mexico with 24 million beneficiaries at the end of 2005.

\subsection{Brazil: Bolsa Familia}

Brazil's CCT experience began with Bolsa Escola, a programme borne out of an experiment on poverty reduction started by the federal district of Brasilia in 1995. According to Cardoso and Souza (2003), the idea was to transfer income to poor families to ensure they keep their children in school. By 1999 the programme was replicated in a total of 61 states and individual municipalities in Brazil. However, since it was becoming difficult for poorer states to implement the programme, it was nationalized in 2001 under the name Bolsa Escola.

As a federal programme, Bolsa Escola was designed to address current poverty reduction, child labour reduction and future poverty reduction. As at 2003, the programme had given US\$700 million to 8.6 million children in 5.06 million households across 5561 municipalities (De Janvry and Sadoulet 2005). In 2003, Bolsa Escola merged with other conditional cash transfer programmes in Brazil to create Bolsa Familia that aimed to reach out to 11.2 million beneficiary households; and grew to be second only to Mexico's Oportunidades in size by 2005 (De Janvry and Sadoulet 2005). As at 2014, Bolsa Familia had benefitted over 14 million families, and received the International Social Security Institute award for Outstanding Achievement in Social Security. Accordingly, the United Nations Food and Agriculture Organisation (FAO) cited the programme as one of the main reasons Brazil was taken off the hunger map (Hellmann, 2015).

\subsection{Nigeria: Household Uplifting Programme}

Nigeria's experience with CCTs did not begin with the Household Uplifting Programme (HUP). A few CCTs and UCTs (Unconditional Cash Transfers) have been or are being implemented in Nigeria. A popular CCT programme in the country is COPE (In Care of the Poor) which, as a pilot programme, aimed at breaking the intergenerational transfer of poverty and the reduction of the vulnerability of the core poor in the society to socioeconomic risks (Holmes et al, 2011). To benefit from the scheme, targeted benefitting households ensured that their children of school-going age attended school regularly, pregnant women attended regular antenatal clinics, and children under five years were immunized and taken to welfare clinics regularly (Aiyede et al, 2015). As at 2012, the programme had benefitted 22,000 households, in 24 states with NGN5 billion contributed by the federal and state governments (Holmes et al, 2011; Aiyede et al, 2015). In 2013, the Nigerian government initiated another CCT pilot programme as a combination of supply and demand-side interventions. It was known as Subsidy Reinvestment and Empowerment 
Programme on Maternal and Child Health (SURE-P MCH). Originally, the initiative was launched in 500 primary health care facilities across Nigeria; subsequently it was scaled up to 1000 facilities (Oduenyi, Ordu and Okoli, 2019). Three other CCT programmes aimed at reducing girls' dropout rates (because of early marriage, specifically in the transition period from primary to secondary school) are currently in operation in Kano, Bauchi and Katsina states.

The Household Uplifting Programme (with the slogan Beta Don Come, meaning better things have arrived) was initiated by the present political dispensation in Nigeria with the primary aim of responding to deficiencies in capacity and lack of investment in human capital of poor and vulnerable households captured in the National Social Register (NSR). The specific outcomes the programme aims to achieve include:

1. improved household consumption,

2. increased use of health and nutrition services,

3. improved school enrolment and attendance,

4. improved environmental sanitation and management,

5. asset acquisition, and

6. sustainable livelihood for beneficiaries (National Cash Transfer Office, 2017).

Its pilot phase began in 2016 with nine states- Borno, Kwara, Bauchi, Cross River, Niger, Kogi, Oyo, Ogun and Ekiti. Available records suggest that these states were chosen because they have an existing social register that identifies the most vulnerable and poorest Nigerians in their locality (Financial Nigeria, 2017). Compared to earlier CCT programmes, the HUP framework is more robust. While previous CCTs were mostly implemented at state level and focused on one intervention area, such as health or education, HUP includes these and also introduces multiple layers of cash transfers (base and top-up). It also exposes beneficiaries to Savings and Group Mobilization sessions that aim at ensuring financial inclusion, in addition to livelihood sessions that prepare grounds for sustainable livelihood when beneficiaries exit the programme. HUP is designed to have nation-wide coverage, and to ensure sustainability, high performing civil servants drive the programme.

\section{Comparative Analysis of the Latin American and Nigerian Conditional Cash Transfer Experience}

The analyses below reveal some areas where a nexus exists between the HUP and the Latin American CCT strategy.

\subsection{Coverage and Transfer Value}

Mexico's Oportunidades benefitted 24 million people by the end of 2005 (Santiago, 2006), and Bolsa Familia supported about 14 million families as of June 2015 with an average payment of R $\$ 167.15$ (Hellmann, 2015). The Nigeria's HUP is also modestly expected to benefit five million families (about twenty-five million individuals) across all the States of the country and the Federal Capital Territory by 2022 (World Bank, 2016). Recent record shows that the HUP makes cash transfers to an estimated one million beneficiary households 
in 31 States and FCT (National Social Investment Office, 2018). Each household under HUP receives a base transfer of NGN5000 (about US\$15) per month. Targeted households will be eligible for an additional top-up transfer of NGN5000 if they participate in any activities that fall under any of these four broad areas- health, education, nutrition, and environment. These are co-responsibilities and each state must choose its co-responsibility area depending on its circumstances and priorities (World Bank, 2016; National Cash Transfer Office, 2017). The average monthly transfer for Bolsa Familia is US\$24, while Oportunidades is US\$20 (Handa and Davis, 2006).

A review of the CCT programmes across the three countries reveals a shortfall in coverage and transfer value. Despite their recorded successes, the reviewed programmes in Latin America remain limited in coverage, in relation to the population of eligible beneficiaries. About 50 per cent of the population in these countries still live in poverty. The HUP has the potential of towing the same line. It targets only 25 million persons in 5 years, in a country where 75 million persons fall below the poverty line (FGN, 2010). Additionally, an international rule of thumb is that a poverty-motivated cash or in-kind transfer should represent between 20 and 40 per cent of the per capita total poverty line in order to be meaningful to the beneficiary (Handa and Davis, 2006). Most of the programmes under examination do not meet this benchmark. Brazil's Bolsa Familia (at 12 per cent) falls significantly below this 20 per cent benchmark. Mexico's Oportunidades however rises a little above 20 percent. In Nigeria, beneficiary households receive about 15 per cent of the per capita total poverty line for the base transfer, and 30 per cent for the top-up transfer (World Bank, 2016).

\subsection{Programme Conditions}

The role of conditionality is one of the most controversial questions about CCT programme design. Conditionality refers to certain requirements that programme beneficiaries must meet in order to receive the cash transfers. Majority of the programmes under study emphasize school attendance and regular visits to health centres as conditionalities. The essence of these conditionalities is to create an incentive and penalty structure that will change participants' behavior and address long-term poverty. Nonetheless, Oportunidades includes nutrition as another component. Families receive an additional monthly transfer for improved food consumption and purchase of nutritional supplements. Bolsa familia requires 85 percent monthly school attendance for all children and adolescents between 6 and 15 years old, and 75 percent monthly school attendance for adolescents between 16 and 17 years (Hellmann, 2015). Under the HUP, beneficiary households must partake in Savings and Group Mobilization (SGM) activities in order to receive the base transfer of NGN5000. Programme conditions for the top-up transfer of NGN5000 include co-responsibilities related to primary school enrollment and attendance, and the use of health services such as immunisation, pre-natal and post-natal care, and child growth monitoring (World Bank, 2016).

The foregoing reveal that low demand in assessing health and education services is one of the foremost reasons for attaching conditionality to cash transfers in Latin America. The assumption is that an adequate supply of these services is available, and therefore demand 
must be created (Ladhani and Sitter, 2020). Interestingly, there is an already high demand for these services in Nigeria. As such the success of the HUP depends on the commitment of various state governments to supplying the requisite co-responsibilities in the form of education facilities or health facilities. Krubiner and Merritt (2017) have thus suggested that in determining programme conditions, the possibility of achieving desired goals, receptivity risks and burdens, and indirect impacts and externalities, should be considered.

\subsection{Exit Strategy/ Programme Duration}

Oportunidades and Bolsa Familia have an eligibility period of three years and two years respectively, after which beneficiaries are recertified. Under the HUP, recertification of poverty status process is carried out every three years to expand and update the National Social Register (NSR). After 18 months on the programme, beneficiaries undergo a six-month Livelihood Training, after which they are expected to come up with a simple business plan. Households that qualify for exit from the programme receive a livelihood grant, while those that do not qualify are recertified and remain on the programme until they graduate out of poverty. The HUP is expected to operate for a period of 5 years (World Bank, 2016).

The short duration of participants' eligibility for the CCT programmes is another similarity among the three countries under study. The exit strategy adopted by these Latin American countries raises a number of concerns. For instance, one contention is whether it is ethical to terminate benefits to households based on a small rise in income; or whether the imposition of short durations and arbitrary exit strategies are in line with the overall objectives of short-term and long-term poverty reduction (Ladhani and Sitter, 2020).

\subsection{Targeting Methods}

The primary aim of targeting in CCT programme design is to increase efficiency in the allocation of cash transfers to the poorest and most vulnerable. The main CCT targeting methods common to the Latin American experience are Proxy Means Tests, Means Tests and Geographical Targeting, or a combination of the three (Handa and Davis, 2006). Means Testing occurs when a trained official assesses a household's eligibility for a programme based on information collected from the household about their income. In Proxy Means Testing, the assessment of household income is based on observation of specific characteristics. While Geographical Targeting occurs when the location where beneficiaries reside is used to determine their eligibility (Coady, Grosh, and Hoddinnott, 2004).

Oportunidades adopts Geographical Targeting in the first stage of the programme, thereafter using the Proxy Means Test. Bolsa Familia, on the other hand, adopts Proxy Means Testing and Indicative Targeting (states and municipalities are given stipulated amounts based on size of potential beneficiaries). However, under HUP, target households are identified through a combination of Geographical Targeting, Proxy Means Targeting, and Community-Based Targeting (CBT). CBT involves the use of local traditional authorities or community group members to select beneficiaries of social protection programmes (Coady et al, 2004). The process begins with the geographical selection of the poorest local government areas in a 
participating state; thereafter the identification of potential beneficiaries is then determined by using a combination of Proxy Means Testing and CBT (World Bank, 2016).

The targeting techniques employed by the CCT programmes in Latin America have often been criticized for been ineffective in reaching the poorest persons (Stampini, 2017). While some non-poor households receive transfers due to errors of inclusion, poor households in other cases do not receive transfers due to errors of exclusion (Devereux et al, 2017). As established above, the HUP uses a combination of Latin American targeting strategies. The previous CCT programmes in Nigeria faced similar challenges, as shown in the omission of eligible participants in the SURE-P MCH CCT pilot programme (Oduenyi et al, 2019).

\subsection{Institutional Structure}

CCT programmes require strong institutional support, especially at the federal level. The Bolsa Familia programme is managed at the national level by the National Secretariat for Citizen Incomes, an office under the Ministry for Social Development and to Combat Hunger (MDS) of Brazil. The main institutional structures for HUP implementation are: (a) National Social Safety Nets Coordinating Office (NASSCO) now set up under the Federal Ministry Of Humanitarian Affairs, Disaster Management And Social Development; (b) the National Cash Transfer Office (NCTO); (c) State Operations Coordinating Unit (SOCU) and State Cash Transfer Unit (SCTU); and (d) implementation offices at the local government level.

In Brazil and Mexico, CCT programmes have a high degree of political support and backing, having survived different governments. As such, these programmes have enjoyed sustainability. However, the Nigerian political situation is different. The penchant for policy makers to abandon programmes and projects of previous administrations, in addition to issues over accountability and transparency of similar programmes in the past, threaten the sustainability of CCT programmes in Nigeria.

\subsection{Funding and Payment System}

One of the critical issues affecting CCT programmes is sustainable funding. Apart from the national treasury, funding for CCT programmes is sourced from international development partners or concessional borrowing. The World Bank and the Inter-American Development Bank are known to support several social transfer strategies. For instance, the Oportunidades programme was financed using income from a reduction in subsidies targeted at the urban middle class (Parker, 2003). Subsequently the programme was financed through funding by the Mexican government and the Inter-American Development Bank (IDB). The World Bank and the Federal Government of Nigeria fund the HUP in a concessional borrowing and counterpart funding arrangement (World Bank, 2016). Interestingly, the Abacha restituted funds form part of the Federal Government's contribution to the programme. While the Federal Government takes care of every other operating costs of the project, state counterpart financing is required in kind, which include office space, staffing costs, equipment, vehicles, and so on.

Clearly, development partner support is vital to the implementation of CCT programmes in the countries under study. But being the main source of funding could form a challenge to 
sustainability, especially in sub-Saharan Africa where these initiatives are rarely supported by national budgets. For instance, Malawi's Mchinji Social Cash Transfer pilot scheme was constrained by fragmented donor funding (Scarlato and d'Agostino, 2016). Therefore, sustainability of the HUP requires putting all of these into consideration, alongside political commitment by policymakers and a sound fiscal policy.

With regard to payment systems, benefits under Bolsa Familia are paid monthly, and can be accessed through the Bolsa Familia cards (used at state programme offices, lottery offices, authorized bank branches, automatic teller machines, and post offices) or through the bank account of the family head. Cash payments are arranged for families who are unable to access any of the e-payment portals. For Oportunidades and HUP, transfers are made every 2 months to poor families. The HUP employs an electronically trackable end-to-end payment system. Payment Service Providers (PSPs) have been designated to make the necessary payments to the beneficiaries. The NCTO transfers the total amount based on the payment schedule to the PSPs. The PSPs make trackable cash payments directly to the primary caregiver in the household every two months, for both base transfers and top up transfers (World Bank, 2016; National Cash Transfer Office, 2017).

Most countries in Latin America that have been successful with CCT programmes are middle-income countries, and they have the requisite technology infrastructure to support electronic payment to programme beneficiaries. Therefore, direct cash payments to beneficiaries are an exception, not the rule. Electronic payments reduce administrative costs and promote accountability. In contrast, Nigeria (like several lower middle income/low-income countries in sub-Saharan Africa) has infantile technology infrastructure, especially in the rural areas where majority of the beneficiaries live.

\subsection{Monitoring and Evaluation}

For Oportunidades and HUP, external bodies carry out independent impact evaluations. Oportunidades has been able to strengthen its legitimacy through credible evaluations carried out by International Food Policy Research Institute (IFPRI). Under the HUP, the National Social Safety Nets Coordinating Office (NASSCO) and the National Cash Transfer Office (NCTO) have a robust internal monitoring and evaluation mechanism. There is also a monitoring and evaluation unit for the National Social Investment Programmes (that include the HUP) at the Federal Ministry of Humanitarian Affairs, Disaster Management and Social Development. Furthermore, independent bodies, such as Civil Society Organizations (CSOs) and other third-party verifiers carry out periodic external impact evaluation of the programme. These processes systematically monitor and evaluate the identification of beneficiaries, the delivery of benefits, and the impact of those benefits (World Bank, 2016). On the other hand, Bolsa Familia, is similarly monitored and evaluated by the Secretariat for Evaluation and Information Management under the Ministry for Social Development and to Combat Hunger (Hellman, 2015).

Obviously, sound monitoring and evaluation mechanisms help strengthen the capacity of social protection instruments and policies. The Latin American countries under review do not only have overarching national policies on social protection, but also possess good 
institutional capacity and complex administrative structures to monitor large-scale programmes. The National Policy on Social Protection in Nigeria was approved recently, and its implementation is on course. Nevertheless, the capacity of state level institutions to implement programmes of this kind is limited.

\section{Conclusion}

As can be deduced from the policy diffusion model, only few of the innovations or policies in operation in many countries are home-grown. The recorded successes of certain policies or ideas in other lands have inspired their adoption and domestication within states. Even so, diffusion does not always bring about the desired impact in the adopting countries. The reasons are not farfetched. Weyland (2006) notes that policy makers tend to readily adopt foreign policies for several illogical reasons, and more often than not, policies are adopted without any rational cost-benefit calculations made by local policy actors. These policy makers embrace successful models as simple solutions that resolve different problems at once. As a result, some government policy decisions have been conditioned by the poor choices made in other countries. Within the last two decades, CCT programmes have become the social protection instruments of choice among developing nations. Available evidence suggests that these programmes made considerable progress in short-term poverty reduction, improved consumption, increased school enrolment and access to primary healthcare in the Latin American countries under review. However, only time and further research will show whether the long-term goal of human capital development has been realized.

Nevertheless, the above comparison has revealed that to a considerable extent, the Nigerian CCT strategy adopted the Latin American model. However, using the policy diffusion framework, this study shows a variation in the policy adoption mechanisms of Latin America and Nigeria. Clearly, the introduction of certain peculiarities from the Latin American CCT experience to cash transfers in sub-Saharan Africa is inappropriate in view of contextual differences between Africa and Latin America; in terms of quality and quantity of service provision, capacity to implement conditionality, socio cultural, ethnic and political factors (Schubert and Slater, 2006). The fact remains that the Latin American model cannot adequately serve as a blueprint for the Nigeria strategy given that underlying conditions in upper middle income Latin American countries are clearly different from those present in low income/lower middle income African countries like Nigeria.

Given the above, this study makes the following recommendations:

a. Provisions of the current National Social Protection Policy should be implemented. This policy will not only guide the development of social protection instruments in the country, but also promote knowledge and awareness of different social protection instruments that may be suitable for addressing the poverty situation in Nigeria.

b. A review of the current CCT programme in Nigeria should be done after two years. The federal government and its development partner, the World Bank should revisit certain areas of the programme, such as programme conditions, targeting, transfer 
value, exit strategy, and payment system. This evaluation should be done with a view to improving programme strategies in the light of present socio-economic realities.

c. Government research institutions and development partners should fund and spearhead research into social protection strategies. The goal should be the development of sustainable programmes that will accommodate the peculiarities of sub-Saharan Africa.

\section{References}

African Development Bank (2018). African Economic Outlook 2018. Retrieved from https://www.afdb.org/fileadmin/uploads/afdb/Documents/Publications/African_Economic_O utlook_2018_-_EN.pdf

Aiyede, E., Sha, P., Haruna, B., Olutayo, A., Ogunkola, E., \& Best, E. (2015). The political economy of social protection policy uptake in Nigeria. Nairobi, Kenya: Partnership for African Social and Governance Research.

Akinola, O. (2014, May). Graduation and social protection in Nigeria: A critical analysis of the COPE CCT Programme. Paper presented at the International Conference on Graduation and Social Protection, Kigali, Rwanda. Retrieved from https://www.ids.ac.uk/files/dmfile/Graduationconferencepaper-Akinola.pdf>

Akinola, O. (2017). Governing social protection in developing countries through community based targeting mechanisms: A case study of Nigeria's COPE Conditional Cash Transfer Programme (Doctoral Dissertation). University of Guelph, Canada. Retrieved from http://hdl.handle.net/10625/56390

Arndt, C., McKay, A., \& Tarp, F. (2016). Growth and poverty in sub-Saharan Africa: UNU-WIDER studies in developing economies. Oxford: Oxford University Press. http://dx.doi.org/10.1093/acprof.oso/9780198744795.001.0001

Attanasio, O., Battistin, E., Fitzsimons, E., Mesnard, A., \& Vera-Hernandez, M. (2005). How effective are conditional cash transfers? Evidence from Colombia. London, England: Institute for Fiscal Studies. https://doi.org/10.1920/bn.ifs.2005.0054

Berry, F., \& Berry, W. (2007). Innovation and diffusion models in policy research. In P. Sabatier (Ed.), Theories of the policy process (pp. 223-260). Colorado, USA: Westview press. https://doi.org/10.4324/9780367274689-8

Cardoso, E., \& Souza, A. (2003). The impact of cash transfers on child labour and school attendance in Brazil. Sao Paulo: Department of Economics, University of Sao Paolo.

Chapman, K. (2006). Using social transfers to scale up equitable access to education and health services. DFID Background Paper. London: Department for International Development.

Coady, D., Grosh, M., \& Hoddinnott, J. (2004). Targeting of transfers in developing countries: Review of lessons and experience. Washington, D.C.: The World Bank. 
https://doi.org/10.1596/0-8213-5769-7

Danaan, V. (2018). Analysing poverty in Nigeria through theoretical lenses. Journal of Sustainable Development, 2(1), 20-31. http://doi:10.5539/jsd.v11n1p20

Dauda, R. (2017). Poverty and economic growth in Nigeria: Issues and policies. Journal of Poverty, 21(1), 61-79. http://doi:10.1080/10875549.2016.1141383

De Janvry, A., \& Sadoulet, E. (2005). Conditional Cash Transfer programs for child human capital development: Lessons derived from experience in Mexico and Brazil. Washington, D.C.: World Bank Development Economics Research Group.

Devereux, S., Masset, E., Sabates-Wheeler, R., Samson, M., Rivas, A., \& Te Lintelo, D. (2017). The targeting effectiveness of social transfers. Journal of Development Effectiveness, 9, 162-211. https://doi.org/10.1080/19439342.2017.1305981

Federal Republic of Nigeria [FGN] (2010). Countdown strategy 2010 to 2015: Achieving the millennium development goals. Abuja, Nigeria: Federal Government Press.

Federal Republic of Nigeria [FGN] (2016). Memorandum of understanding between the Federal Government of Nigeria (acting through the Office of the Vice President) and State Governments on National Social Safety Net Programme. Abuja, Nigeria: Presidency.

Financial Nigeria (2017, January 3). FG Commences Cash Transfer Payment in Nine States Retrieved

from http://financialnigeriacom/fg-commences-conditional-cash-transfer-payment-in-nine-states-su stainable-photovideo-details-661.html. accessed on 09/10/17

Fiszbien, A., \& Schady, N. (2009). Conditional cash transfers: Reducing present and future poverty. Washington DC: The World Bank. https://doi.org/10.1596/978-0-8213-7352-1

Freeland, N. (2007). Superfluous, pernicious, atrocious and abominable? The case against conditional cash transfers. IDS Bulletin, 38(3), 75-78. https://doi.org/10.1111/j.1759-5436.2007.tb00382.x

Garcia, S., Harker, A., \& Ricaurte, J. (2016). The impact of conditional cash transfer programs on educational aspirations in Columbia. Bogota, Columbia: University of Los Andes. https://doi.org/10.2139/ssrn.2927139

Gilardi, F., \& Wasserfallen, F. (2018). The politics of policy diffusion. European Journal of Political Research, 58(4). https//doi.org/10.1111/1475-6765.12326

Graham, E., Shipan, C. \& Volden, C. (2013). The diffusion of policy diffusion research in political science. British Journal of Political Science, 43(3), 673-701. https//doi:10.1017/S0007123412000415

Handa, S., \& Davis, B. (2006). The experience of conditional cash transfers in Latin America and the Caribbean. Development Policy Review, 24(5), 513-536. https://doi.org/10.1111/j.1467-7679.2006.00345.x 
Hanlon, J., Barrientos, A., \& Hulme, D. (2010). Just give the money to the poor: The development revolution from the Global South. Vancouver, USA: Kumarian Press.

Hellmann, G. (2015). How does Bolsa Familia work? Best practices in the implementation of conditional cash transfer programs in Latin America and the Caribbean. Washington, D.C.: Inter-American Development Bank

Holmes, R., Samson, M., Magoronga, W., \& Akinrimisi, B. (2011). The Potential for cash transfers in Nigeria. London, UK: Overseas Development Institute.

Howlett, M., Ramesh, M. \& Saguin, K. (2018). Diffusion of CCTs from Latin America to Asia: The Philippine 4Ps Case. Public Administration Review, 52(3). http://dx.doi/10.1590/0034761220170020

Kinnunen, J. (1996). Grabriel Tardeas: A founding father of innovation diffusion research. Acta Sociologica, 39(4), 431. http:// doi: 10.1177/000169939603900404.

Krubiner, C., \& Merritt, M. (2017). Which strings attached: Ethical considerations for selecting appropriate conditionalities in conditional cash transfer programmes. Journal of Medical Ethics, 43(3), 167-176. https://doi.org/10.1136/medethics-2016-103386

Kuhlmann, J., De Reufels, D., Schlichte, K. \& Nullmeier, F. (2019). How social policy travels: A refined model of diffusion. Global Social Policy, 1(1). https://doi.org/10.1177/1468018119888443

Ladhani, S., \& Sitter, K. (2020). Conditional cash transfers: A critical review. Development Policy Review, 38, 28-41. https://doi.org/10.1111/dpr.12416

Legarde, M., Haines, A., \& Palmer, N. (2009). The impact of conditional cash transfers on health outcomes and use of health services in low and middle income countries. Cochrane Database System Review, 4(4). https:// doi: 10.1002/14651858.CD008137

Lund, F., Noble, M., Barnes, H., \& Wright, G. (2008). Is there a rationale for conditional cash transfers for children in South Africa? Transformation: Critical Perspectives on Southern Africa, 70(1), 70-91. https://doi.org/10.1353/trn.0.0038

Maggeti, M. \& Gilardi, F. (2016). Problems (and solutions) in the measurement of policy diffusion mechanisms. Journal of Public Policy, 36(1), 87-107. https://doi.org/10.1017/S0143814X1400035X

Motta, M. (2018). Policy diffusion and directionality: Tracing early adoption of offshore wind policy. Review of Policy Research, 35(3), 398-421. https://doi.org/10.1111/ropr.12281

National Bureau of Statistics [NBS] (2010). 2009-10 National poverty rates for Nigeria, (abridged report).Retrieved from http://nigerianstat.gov.ng/elibrary?queries[search]=poverty\%20rate.

National Cash Transfer Office (2017). Operational manual for the Household Uplifting Programme in Nigeria. Abuja, Nigeria: Presidency. 


\section{Macrothink}

Journal of Public Administration and Governance

ISSN 2161-7104

2020, Vol. 10, No. 3

National Social Investment Office (2018). Investing in our people: A Brief on the National

Social Investment Programmes in Nigeria. Retrieved from

https://www.google.com/url?sa=t\&source=web\&rct=j\&url=http://npower.gov.ng/nsip.pdf\&ve $\mathrm{d}=2$ ahUKEwjEx5OItofqAhUDDmMBHanAlMQFjAAegQIARAB\&usg=AOvVaw3Pv6g Ows_mDmLpdB-mAKd

Obinger, H., Schmitt, C. \& Starke, P. (2013). Policy diffusion and policy transfer in comparative welfare state research. Social Policy and Administration, 47(1), 111-129. https://doi.org/10.1111/spol.12003

Oduenyi, C., Ordu, V., \& Okoli, U. (2019). Assessing the operational effectiveness of the Maternal and Child Health $(\mathrm{MCH})$ conditional cash transfer pilot programme in Nigeria. BMC Pregnancy Childbirth 19, 298. https://doi.org/10.1186/s12884-019-2418-0

Oliveira, O., \& De Faria, C. (2017). Policy transfer, diffusion and circulation: Traditions and the state of the discipline in Brazil. Novos Estudos CEBRAP, 36(1), 13-32. http://dx.doi.org/10.2509/s0101.3300201700010001.

Oluwatayo, I., \& Ojo, A. (2018). Walking through a tightrope: The challenge of economic growth and poverty in Africa. The Journal of Developing Areas, 52(1), 60-69. http:// doi:10.1353/jda.2018.0004

Orton, I. (2014). Conditional cash transfers and the human rights to social security. Social Protection and Human Rights Platform. Retrieved from http://socialprotection humanrights.org/expertcom/conditional-cash-transfers-and-the-human-right-to-social-security I

Owusu-Addo, E., Ranzaho A., \& Smith, B. (2019). Cash transfers and the social determinants of health: A conceptual framework. Health Promotion International, 34(6), 106-118. http:// doi.org/10.1093/heapro/day079

Parker, S. (2003). Case Study: The Oportunidades program in Mexico. Retrieved from http://info.worldbank.org/etools/library/latestversion.asp?36298>

Rogers, E. (2003). Diffusion of Innovations. (5th ed.). New York: Free Press.

Sandberg, J. (2015). Between poor relief and human capital investments-Paradoxes in hybrid social assistance. Social Policy and Administration, 50(3). https://doi.org/10.111/spol.12111.

Santiago, L. (2006). Progress against poverty: Sustaining Mexico's PROGRESAOportunidades program. Washington DC: Brookings.

Saunders, P. (2018). Monitoring and addressing global poverty: A new approach and implications for Australia. The Economic and Labour Relations Review, 29(1) 9-23. http://doi:10.1177/1035304618756208

Scarlato, M., \& d'Agostino, G. (2016). The political economy of cash transfers: A comparative analysis of Latin American and sub-Saharan African experiences. Bonn: German Development Institute. 
Schady, N., \& Araujo, M. (2008). Cash transfers, conditions, and school enrollment in Ecuador. Economia, 8(2), 43-77. http://doi: 10.1353/eco.0.0004

Schubert B., \& Slater, R. (2006). Social cash transfers in low-income African countries: Conditional or unconditional? Development Policy Review, 24(5), 571-578. https://doi.org/10.1111/j.1467-7679.2006.00348.x

Sepulveda, M. (2011). Links between social protection and human rights. Speech delivered to the Commission on Social Development. Geneva, Switzerland: United Nations.

Stampini, M. (2017). Beneficiary identification and management of the rosters of beneficiaries. In P. Ibarrarán, N. Medellín, F. Regalia, \& M. Stampini (Eds.) How Conditional Cash Transfers Work: Good Practices After 20 Years of Implementation. Retrieved from https://publications.iadb.org/en/how-conditional-cash-transfers-work

Standing, G. (2014). Conditionality and human rights. Social protection and human rights platform.

Retrieved

from

http://socialprotectionhumanrights.org/expertcom/conditionality-and-human-rights.

Sugiyama, N. (2011). The diffusion of conditional cash transfer programs in the Americas. Global Social Policy, 11(2-3), 250-278. http://doi:10.1177/1468018111421295

United Nations Development Programme [UNDP] (2009). 2008-2009 Human Development Report Nigeria: Achieving Growth with Equity. Abuja, Nigeria: UNDP.

Way, C. (2005). Political insecurity and the diffusion of financial market regulation. The Annals of the American Academy of Political and Social Science, 598, 125-144. http://doi:10.1177/0002716204272652

Weyland, K. (2006). Bounded rationality and policy diffusion. Princeton, NJ: Princeton University Press.

Whetten, J., Fontenla, M., \& Villa, K. (2019). Opportunities for higher education: The ten-year effects of conditional cash transfers on upper secondary and tertiary enrolments. Oxford Development Studies, 47(2), 222-237. http://doi:10.1080/13600818.2018.1539472.

World Bank (2016). Project appraisal document on a proposed loan/credit in the amount of US $\$ 500$ million to the Federal Republic of Nigeria for a National Social Safety Nets Project. Washington DC: World Bank.

World Bank (2017). Monitoring integrated global poverty: Report of the Commission on Global Poverty. Washington DC: World Bank.

\section{Copyright Disclaimer}

Copyright for this article is retained by the author(s), with first publication rights granted to the journal.

This is an open-access article distributed under the terms and conditions of the Creative Commons Attribution license (http://creativecommons.org/licenses/by/4.0/). 